\title{
Estabilidad, circularidad y origen: una lectura fenomenológica de la concepción política de la justicia
}

\author{
Stability, Circularity and Origin: \\ A Phenomenological Reading of Political Conception of Justice
}

AGUSTÍN PALOMAR TORRALBO*

\begin{abstract}
Resumen: Este trabajo propone un acercamiento al liberalismo político desde la fenomenología. Comienza con la descripción del espacio político democrático como aquel que puede ser abordado desde la correlación de la facticidad institucional y los principios de la justicia. En un segundo momento, profundiza en cómo Rawls entiende la formación de este espacio desde el constructivismo político para evitar el compromiso con una filosofía trascendental. Finalmente, el trabajo hace una relectura de la concepción política de la justicia desde la fenomenología husserliana atendiendo a los conceptos de origen, actitud fenomenológica, epojé y reducción.

Palabras clave: fenomenología, liberalismo político, constructivismo, justicia, estabilidad, posición original.
\end{abstract}

\begin{abstract}
This article proposes an approach to political liberalism from phenomenology. It begins with the description of the democratic political space as one that can be studied from the correlation of institutional facticity and principles of justice. Secondly, it digs into how Rawls understands the formation of this space from political constructivism to avoid commitment to a transcendental political philosophy. Finally, the article takes a reading of the political conception of justice from Husserl's phenomenology paying attention to the concepts of origin, phenomenological attitude, epoché and reduction.
\end{abstract}

Keywords: phenomenology, political liberalism, constructivism, justice, stability, original position.

Fecha de recepción: 13/11/2014. Fecha de aceptación: 16/05/2016.

* Doctor en Filosofía por la Universidad de Murcia (UM). Profesor de secundaria en el IES La Madraza de Granada. Mis líneas de investigación se orientan hacia la fenomenología, la metafísica y la filosofía práctica. Algunas de mis últimas publicaciones son: "Hacia una restauración del sentir a partir de la fenomenología del cuerpo de Michel Henry", Pensamiento, Vol., 72, n 270, 2016, pp. 85-101; "Para una fenomenología del arte y la filosofía a luz de la metafísica hegeliana", Estudios filosóficos, Vol. 64, n 185, 2015, pp. 63-81. El trabajo que aquí se presenta se inscribe dentro del proyecto de elaboración de una fenomenología de lo político que tiene como objetivo responder a la cuestión acerca de cómo se constituye el éthos democrático desde una lectura fenomenológica de la concepción política de la justicia. A este primer trabajo, le seguirá otro en el cual se replantee la relación entre Hegel y Rawls en torno al problema del trasfondo ético en las sociedades democráticas. Un tercer trabajo, partiendo de aquí, abordará el problema de la constitución del espacio político democrático desde una fenomenología de los valores políticos.Contacto: agupalomar@yahoo.es 


\section{Estabilidad, facticidad institucional y trasfondo social justo}

Puede decirse, usando la terminología fenomenológica, que para Rawls hay un a priori de correlación entre el grado de estabilidad del orden social y el grado de consenso político alcanzado para esa sociedad. A mayor estabilidad social, mayor posibilidad de alcanzar un consenso político, y a mayor consenso político, mayor posibilidad de mantener la estabilidad del orden social. Ciertamente, ha de haber una estabilidad mínima en la sociedad para que pueda llevarse a cabo un consenso; pero, a su vez, los consensos rehabilitan, refuerzan, y mantienen la estabilidad social. En El liberalismo político ${ }^{1}$ Rawls ensaya el camino del consenso como aquello que da estabilidad a sociedades democráticas profundamente divididas por el pluralismo. La concepción política de la justicia lleva la pretensión de extender el consenso, más allá de las cuestiones en torno a derechos básicos, a cuestiones de justicia social tales como la igualdad de oportunidades y la equitativa distribución de bienes. A medida que el consenso político es más amplio y profundo, mayor es la estabilidad de una sociedad a lo largo del tiempo, y a medida que su estabilidad es mayor, más fácil es ampliar y profundizar el foco del consenso ${ }^{2}$.

Como hemos apuntado, este a priori parte del supuesto de que nuestras sociedades se hallan profundamente divididas por conflictos que no pueden ser completamente reducidos, superados y suprimidos pero que tienen que ser afrontados buscando acuerdos y consensos acerca de lo fundamental y común. Sólo desde perspectivas ideológicas que falsean la realidad y desde perspectivas doctrinarias que no quieren verla pueden negarse los conflictos políticos. "Sólo los ideólogos y los visionarios -escribe Rawls- no logran experimentar los profundos conflictos de valores políticos y entre estos valores y los valores no políticos"3. Señala Rawls que, en el modelo del liberalismo político, para garantizar la estabilidad bastaría que se cumplieran tres condiciones: i) las instituciones políticas, sociales y económicas de una sociedad tendrían que regularse de acuerdo con la concepción política de la justicia; ii) sobre esta misma concepción, que regula tanto derechos políticos como derechos sociales, tendría que lograrse un consenso; y iii) esta concepción tendría que entrar en juego si la conflictividad afectara tanto a las cuestiones constitucionales fundamentales como a las cuestiones de justicia básica ${ }^{4}$. La estabilidad, en conclusión, depende de que la concepción política de la justicia regule las instituciones y arbitre la discusión en el espacio político cuando queda afectada la estructura institucional fundamental del régimen democrático. Ahora bien, estas dos condiciones sólo pueden satisfacerse sobre la base de la segunda: la posibilidad misma de que pueda establecerse

1 Rawls, J., Political liberalism, 2a ed. aum., New York, Columbia University Press, 1996. [V. e.: El liberalismo político, trad., Antoni Domènech, Barcelona, Crítica, 1996. Cito por esta traducción hecha a partir de la $1^{\mathrm{a}}$ edición, la cual no incluye los siguientes textos de la edición aumentada: "Reply to Habermas", The Journal of Philosophy (New York), Vol. 92, n 3, March 1995, pp. 132-180 y "The Idea of Public Reason Revisited", University of Chicago Law Review (Chicago), Summer 64, 1997, pp. 765-807.]

2 El problema de la estabilidad fue objeto del importante artículo de Brian Barry: "John Rawls and the Search for Stability", Ethics (Chicago), Vol. 105, n . 4, Julio 1995, pp. 874-915. Para un análisis del problema de la estabilidad a partir de una crítica a este artículo vid.: Seleme, H., "El problema de la estabilidad", Doxa. Cuadernos de filosofía del derecho, (Alicante), $\mathrm{n}^{\circ} 24,2001, \mathrm{pp} .297-318$.

3 Ralws, J., El liberalismo..., p. 75. Trad. modificada.

4 Cf. Rawls, J., El liberalismo..., p. 74. 
un consenso sobre la concepción política de la justicia. Si este no se produjera, entonces no podría garantizarse la estabilidad social y el espacio político que se construye con las instituciones del régimen liberal quedaría arruinado. La correlación entre estabilidad y consenso viene a recaer, por tanto, en la posibilidad de que aquellos que se hallan enfrentados en el espacio público lleguen al acuerdo de aceptar esos principios básicos que recoge la concepción política de la justicia. Como sabemos, el overlapping consensus tiene como objetivo último recabar el apoyo para esta concepción de la justicia.

Ahora bien, para Rawls el consenso no tiene como objetivo establecer los principios que conforman la concepción de la justicia. Esto correspondería a una suerte de procedimentalismo mediante el cual se afanarían las diferentes partes que participan en un consenso en encontrar los principios de la justicia. La concepción política de la justicia no decide cuáles son estos principios sino que estos ya se encuentran latentes en la tradición de las sociedades democráticas. "La desconfianza de Rawls hacia la neutralidad meramente procedimental -ha afirmado Melero de la Torre- le hace depositar la promesa de consenso en las ideas y valores sustantivos de justicia preponderantes en las prácticas y tradiciones democráticas"5. El filósofo político, que trata de espejar una concepción de la justicia, es el que, a través de la reflexión, los hace aparecer dejándolos en franquía para que puedan ser objeto de un consenso. Este rechazo al mero procedimentalismo queda recogido en la firme tesis de Rawls de que el contenido de la concepción de la política de la justicia "sale de las entrañas de una tradición política determinada..."6. Esta tradición ofrece las instituciones políticas, sociales y económicas que conforman la estructura básica de una sociedad democrática así como el conjunto de las ideas y de los valores sobre los que se asientan estas instituciones.

El espacio político democrático, de este modo, está internamente constituido por una trama de instituciones que estructuran y ordenan la sociedad dándole estabilidad. Si la democracia puede entenderse metafóricamente como un espacio político y público, este, antes que representárnoslo como un espacio vacío donde los diferentes grupos sociales entrarían para habitarlo, hay que verlo como un sistema de instituciones en el que ya se está pero en el que, por su factura humana, también puede transformarse, mantenerse o perderse. En este sentido, siguiendo una indicación heideggeriana, puede afirmarse que para Rawls una persona cuando nace ya es un ser-en-el-mundo desde una perspectiva política/institucional y este entramado vertebra su persona hasta el momento de su muerte. Las personas siempre se relacionan en la estructura básica de la sociedad y las relaciones que se establecen entre ellas ya son en la mediación de las instituciones políticas. No pueden concebirse ni las personas ni sus relaciones sociales sin esta mediación. Esto es lo que significa para Rawls que la sociedad política sea cerrada: "Sólo -afirma- dentro de ella llegamos a ser, y no ingresamos o salimos de ella voluntariamente, ni lo podemos hacer"7. Esta es nuestra condición política humana más básica, aquello que podríamos llamar, siguiendo a Habermas, la "facticidad

5 Melero de la Torre, M. C., Rawls y la sociedad liberal. El proyecto de la neutralidad política, Madrid, Plaza y Valdés Editores, 2010, pp. 54-55.

6 Rawls, J., El liberalismo..., p. 44.

7 Rawls, J., El liberalismo..., p. 167. 
político/institucional"8. Por tanto, la búsqueda de la estabilidad a través del consenso ya viene precedida del entretejimiento de las instituciones que definen nuestra facticidad como seres políticos. Incluso nuestro nacimiento y nuestra muerte, más allá de que sean acontecimientos naturales, vienen dados como una entrada y una salida de las instituciones políticas.

Este espacio político en la democracia tiene su origen en una Constitución. Pero, para Rawls, no cualquier tipo de Constitución ha de ser adoptada como marco general para la democracia sino aquella que sea más justa, lo cual sólo puede dirimirse, evidentemente, bajo los principios de la justicia9 ${ }^{9}$. Bajo el liberalismo político, las instituciones democráticas no sólo señalarían, por eso, desde su origen, los límites en los cuales se desenvuelve nuestra vida en tanto que vida política sino que además estructurarían esa vida según una idea de justicia. Entre este factum y aquellos principios, la Constitución tiene una tarea de mediación. Y, a su vez, entre la Constitución y el tejido social hay todavía dos mediaciones: la de las leyes políticas, económicas y sociales aprobadas en la etapa legislativa que debieran preservar los principios de la justicia preservando, a su vez, en su aprobación, los principios constitucionales, $\mathrm{y}$, en segundo lugar, la de las instituciones que ejecutan, administran y hacen cumplir esas leyes ${ }^{10}$.

En la Constitución, en el espacio político que instituye, en el marco jurídico que define y en los valores que promueve, arraigan las condiciones bajo las cuales puede darse la estabilidad social en una democracia. Pero la Constitución tiene otro valor añadido para el liberalismo político: ella es el resultado de un tipo determinado de consenso: el consenso constitucional ${ }^{11}$. Este consenso es importante en la medida en que la Constitución surge del logro de un acuerdo y de un entendimiento político que señala desde el origen la posibilidad de dejar a un lado las posiciones sectarias, fundamentalistas y excluyentes para alcanzar con la máxima legitimidad democrática posible el acuerdo en torno a los principios constitucionales.

Ahora bien, en el espacio político definido por el liberalismo no basta con el consenso constitucional que da origen al sistema político democrático, ni basta para lograr la estabilidad deseada con la apelación a este consenso primero, sino que es necesario implicar a aquellos ciudadanos que en el espacio político suscriben doctrinas razonables. Este conjunto de ciudadanos tiene la irrecusable tarea de dar apoyo a aquella concepción de la justicia que mejor pueda dar estabilidad a las sociedades democráticas. A las doctrinas comprehensivas razonables, a pesar de su interno enfrentamiento, les compete esta tarea de actualizar, ampliar y profundizar el consenso constitucional en el espacio de libertad abierto en la democracia. El liberalismo político parte así del supuesto de que un subconjunto de las doctrinas comprehensivas o sustantivas, que conviven en el espacio político de la democracia, son razonables y de que ponen a prueba su razonabilidad en el apoyo a un régimen constitucional si este está configurado desde

8 Para la lectura habermasiana de Rawls en torno a la relación entre facticidad y normatividad vid.: Palomar Torralbo, A., "Tensión y complejidad en la teoría crítica de la sociedad y discursiva del derecho", Alfa. Revista de la Asociación andaluza de filosofía, Vol. XXI, 2007, pp. 30-51. Para una ampliación del debate entre Rawls y Habermas vid.: Finlayson, J. G. and Freyenhagen F. (ed.), Habermas and Rawls. Disputing the Political, New York, Routledge, 2011.

9 Cf. Rawls J., El liberalismo..., p. 374.

10 Cf. Parekh, B., Pensadores políticos contemporáneos, Madrid, Alianza Editorial, 2005, pp. 287-288.

11 Para una lectura de la novedad que supone el consenso constitucional en la filosofía política de Rawls vid:: Rex, M.: “Overlapping consensus”en Mandle, J. and Reidy D. A. (ed.), A Companion to Rawls, Oxford, WileyBlackwell, pp. 283-285. 
los principios de la justicia. La razonabilidad se sostiene en aquellos sujetos que, aun viviendo en la cosmovisión de una doctrina comprehensiva, ven la necesidad de apoyar públicamente aquel sistema político que genera un sistema social más justo y, por ello, deciden sumarse mediante un consenso al apoyo de aquella concepción de la justicia que mejor puede hacerlo posible. Para Rawls esta concepción es la concepción política de la justicia ${ }^{12}$.

La relevancia del pensamiento de Rawls no está, principalmente, en la defensa del régimen y del consenso constitucional para garantizar la estabilidad social, sino en la defensa de que las cuestiones estrictamente constitucionales no puede hacerse al margen de las cuestiones de justicia social y de un consenso amplio y profundo en torno a ellas. Es difícil, por otra parte, que los propios principios constitucionales sean aceptados, reconocidos y apoyados si quienes son sujetos de los derechos de ciudadanía en tal régimen no ven que esos principios generan un sistema justo. Sin justicia social no es posible, a largo plazo, mantener un régimen político de libertades. Por ello, no sólo la defensa de las libertades es importante para la justicia social sino también la defensa de la justicia para las libertades.

Las instituciones de la democracia tienen que propiciar, de este modo, que se incardinen en el seno de la sociedad los principios de la justicia. "El papel de las instituciones que pertenecen a la estructura básica -afirma Rawls- es asegurar un trasfondo justo a las condiciones en que se dan las acciones de los individuos y de las asociaciones"13. Aunque no pueda eliminarse la conflictividad entre las diferentes concepciones del bien defendidas por las diversas doctrinas comprehensivas, el liberalismo político apela a que estas doctrinas reconozcan, apoyen y defiendan los principios de la justicia. Como insiste Rawls, el propósito del liberalismo no está "en hallar vías de imponer esa concepción una vez que estamos convencidos de que es válida"14, sino en ir ganándose un apoyo amplio y profundo apelando siempre a la razonabilidad de los ciudadanos. Esto tiene una doble consecuencia: por un lado, requiere que ese apoyo se traduzca en una justificación razonada en el espacio público; pero de otro, esta justificación no puede quedar nunca convertida en una fundamentación filosófica, dado que no hay una razón en sí o suficiente para que la concepción política de la justicia pueda ser tomada como verdadera y, eventualmente, por serlo, impuesta a la sociedad. Su legitimidad no viene dada por ser predicada como verdadera de manera incondicional sino por ser reconocida y sostenida desde las razones de los que participan en el espacio público democrático.

\section{Circularidad, fundamentación filosófica y constructivismo}

Pues bien, si esta breve exposición de la concepción política de la justicia es correcta, entonces aquella correlación primera de la que partíamos entre estabilidad y consenso ha quedado abierta a estas otras: en primer lugar, la correlación entre un consenso constitucional y el llamado consenso entrecruzado y, en segundo lugar, la correlación entre el consenso entrecruzado y ese trasfondo social justo que tiene que ser asegurado por las institucio-

12 Para la razonabilidad vid.: Muguerza, J., "Razonabilidad" en Cerezo Galán, P. (ed.), Democracia y virtudes cívicas, Madrid, Biblioteca Nueva, 2005, pp. 121-129; Muguerza, J., "Prólogo" a Melero de la Torre, M. C., op. cit., pp. 16-17.

13 Rawls, J., El liberalismo..., p. 302.

14 Ibíd., p 175. 
nes. Como puede observarse, cada una de estas correlaciones parece dibujar un círculo: un círculo, primero, entre estabilidad y consenso, el cual recaería, a su vez, en el círculo formado por las instituciones del régimen constitucional y los principios de la justicia, el cual, a su vez, recaería en el círculo que se forma entre el consenso entrecruzado para la concepción política de la justicia y el trasfondo ético de una sociedad. Estos círculos, como también hemos resaltado, no se dibujarían en el vacío, ni serían el resultado de una suerte de procedimentalismo, sino que cabría verlos, más o menos trazados, en las instituciones, valores y principios de la tradición política de nuestras sociedades democráticas y describirían, fundamentalmente, el modo como se relacionan, en el espacio público democrático, la experiencia y los principios de la justicia. Bajo la figura del círculo, podemos aún concretar más el contenido de estas co-relaciones de la siguiente manera: en primer lugar, a medida que el consenso constitucional esté más presente en el espacio político de las sociedades democráticas, más fácil será poner el foco del consenso entrecruzado en la concepción política de la justicia; pero, a su vez, a medida que el consenso entrecruzado atraiga hacia sí y apuntale a esta concepción de la justicia con las razones provenientes de las diferentes doctrinas sustantivas, más fácil será valorar el consenso constitucional que dio origen al sistema democrático. En segundo lugar, a medida que el trasfondo de una sociedad se constituya desde los principios de la justicia, más fácil será aportar razones desde las diferentes doctrinas comprensivas razonables para el consenso entrecruzado; pero, a su vez, a medida que aparezcan y predominen en el espacio público estas razones, más fácil será constituir un trasfondo social justo. En tercer lugar, a medida que una sociedad mantenga vivo su vínculo con la tradición democrática de pensamiento, más fácil será que en ella puedan valorarse los principios, valores e instituciones democráticas; pero, desde el otro polo de la relación, a medida que se vayan fortaleciendo estas instituciones, teniéndose en cuenta sus principios y valores en el espacio público, con más claridad podrá verse a esa sociedad como dependiente y heredera de la tradición política democrática, lo cual ayudará, naturalmente, a fortalecer sus instituciones. En cuarto lugar, a medida que los individuos reconozcan la facticidad político institucional en la que se desarrolla su vida como ciudadanos, más fácil será el reconocimiento de la autoridad pública de la Constitución; pero también, a su vez, en la medida que haya un mayor desarrollo en una sociedad de la cultura liberal en torno a los principios y valores constitucionales, más fácil será que los ciudadanos se sientan responsables y copartícipes de sus instituciones democráticas. Por último, a medida que los ciudadanos apoyen mediante sus razones una concepción de la justicia, esta estará presente con un mayor consenso en el espacio público; pero, a la vez, a medida que haya un mayor consenso en torno a unos principios de la justicia, mayor facilidad habrá para que los ciudadanos busquen en sus diferentes concepciones del bien las mejores razones para apoyar los principios de la justicia.

Esta descripción de las correlaciones, que apuntan intencionalmente a una circularidad, recuerda el método hegeliano para la ciencia descrito al final de la Ciencia de la lógica como un Kreis von Kreisen ${ }^{15}$. Pero, en el contexto de El liberalismo político, el factum del pluralismo y la propia facticidad político/institucional señalan la imposibilidad de que esas relaciones terminen, finalmente, cerrándose en el círculo de un concepto y, por tanto,

15 Cf. Hegel, G.W.F., Werke 6, Frankfurt a. M., Suhrkamp Verlag, 1969, p. 572. 
de una ciencia filosófica. En la distancia del liberalismo de la metafísica de Hegel, la tarea del pensamiento queda confinada a proporcionar una justificación que no puede alcanzar el grado de una fundamentación, la fuerza de la razón, que se abría paso en la historia, a la necesidad de un uso de la razón como razonabilidad, la eticidad, como constitución moral de una sociedad, a un trasfondo social justo que funciona como marco de los consensos, la propia experiencia con-vertida en ciencia, en la búsqueda de un equilibrio entre nuestras convicciones morales y el modelo teórico propuesto por la filosofía política, y, por último, el poder de constitución de la razón práctica, en la construcción de una concepción política de la justicia que tiene que ser expuesta, apoyada y defendida en el espacio público.

El liberalismo rechaza así una ciencia filosófica de la política donde las diferencias y los conflictos pueden superarse definitivamente y acepta la tesis de que, en su interior, los conflictos entre distintas concepciones sustantivas de tipo religioso, filosófico y moral no podrán ser erradicados. No hay garantía racional de que el camino de la reflexión cierre las heridas de los conflictos, ni de que, de estas heridas, no surjan otros nuevos. Pero además, en nuestras sociedades, el pluralismo ha emergido con tanta fuerza que hace difícil e improbable no sólo ya la recapitulación del conflicto en concepto, indicando esto el lugar -la facticidad- de nuestra experiencia social y política, sino la posibilidad misma de un acuerdo previo en torno a una autoridad moral, a un texto sagrado, a un orden de valores morales o a una concepción natural y universal de la ley ${ }^{16}$. El pluralismo hace inviable alcanzar un acuerdo si este viene ya predefinido desde un orden moral religioso, filosófico o natural/jurídico. Ni una doctrina del derecho natural, ni una moral religiosa, ni una moral filosófica pueden ofrecer principios comunes para regir la vida política de los ciudadanos y de las comunidades. El liberalismo político niega que la esfera política, bajo un régimen democrático de libertades marcado por el signo del pluralismo, pueda ser fundamentada en alguna de estas doctrinas. Esta debe quedar al margen de las concepciones metafísicas, morales y religiosas manteniendo un cierto escepticismo acerca de la verdad de estas concepciones y, por tanto, un escepticismo acerca de la posibilidad de que en una de ellas pueda encontrarse la base para una fundamentación de los principios políticos como principios compartidos por todos.

Profundizando en esta idea, hemos de decir que el liberalismo político rechaza toda suerte de fundamentación de la concepción política de la justicia en una concepción trascendente o trascendental del bien. La primera correspondería a una fundamentación de tipo religioso, la segunda a una de tipo filosófico. Dejemos a un lado la fundamentación basada en una moral religiosa y centrémonos en la segunda ${ }^{17}$. Una fundamentación de tipo filosófico puede adoptar para Rawls la forma de una doctrina realista o idealista. Según la primera, la fundamentación tendría que darse en un orden independiente de valores, como en el intuicionismo moral ${ }^{18}$. Pero el liberalismo político no puede comprometerse con un orden metafísico de valores cuya subsistencia sería independiente de los sujetos que los conocen. Un orden de valores objetivo sería defendido por lo que Rawls llama "realismo

16 Cf. Rawls, J., El liberalismo..., p. 128.

17 Para el problema de la religión y de la moral religiosa en el contexto del liberalismo político vid.: Dombrowski, D. A., Rawls and Religion. The Case for Political Liberalism, Albany, State University of New York Press, 2001.

18 Cf. Rawls, J., El liberalismo..., p. 126. 
trascendental"19. Pero también el liberalismo ha de dejar atrás una fundamentación idealista transcendental al modo kantiano. Rawls rechaza la fundamentación transcendental kantiana en tanto que su ideal de autonomía encierra una concepción moral comprehen$\operatorname{siva}^{20}$. Aunque el liberalismo político ponga un cierto ideal de autonomía en el foco del consenso entrecruzado, la autonomía al modo kantiano no puede ser adecuada para "proporcionar una base pública de justificación"21. El sentido más profundo para Rawls del ideal kantiano de autonomía tiene que ver con la capacidad del sujeto moral para realizar un reino de valores políticos. Este tipo de autonomía es adjetivada como "constitutiva". "A diferencia del intuicionismo racional -afirma Rawls- la autonomía constitutiva dice que el llamado orden independiente de valores no se constituye a sí mismo, sino que es constituido por la actividad, real o ideal, de la razón práctica (humana) misma”22.

Una filosofía práctica fundamentada metafísicamente es considerada por Rawls también como una concepción comprehensiva más que ya no puede tener la tarea de fundamentar la política en un universo de valores al modo del realismo platónico o de constituirla produciéndola al modo del idealismo kantiano. La política queda, de este modo, infundada respecto a un orden trascendente de valores en la religión, respecto a una ciencia filosófica o metafísica pero también, como hemos visto en referencia a Kant, respecto a un orden moral trascendental. Ciertamente, aceptar esto significa que la filosofía ha perdido la posición privilegiada de erigirse en filosofía primera desde el punto de vista teórico y práctico, y que ella ya no puede, ni metafísica, ni trascendente, ni trascendentalmente determinar moralmente el orden de la política. Esta pérdida de la posición central de la filosofía también se manifiesta en que para Rawls la filosofía, como filosofía primera, es sólo otra doctrina comprehensiva más y no puede, por tanto, arrogarse el derecho de considerarse a sí misma como la doctrina más verdadera. Como concepción comprehensiva, la filosofía ha de someterse al mismo procedimiento de exposición y aceptación que las demás doctrinas comprehensivas teniendo que descomprometerse con la tarea histórica de ofrecer un fundamento a la política. Con ello, ciertamente, se renuncia a la incondicionalidad, necesidad y universalidad de un principio moral racional que rija para el orden práctico; pero es, bien visto, lo que hace posible que, el liberalismo político, como una doctrina libre de certezas metafísicas, se asiente históricamente en una tradición política determinada de pensamiento ${ }^{23}$ y lo que conlleva que no pueda eludir en su justificación las condiciones sociales de su tiempo. Desde la facultad política de la razonabilidad, la necesidad de la justificación significa que el espacio político, como espacio público, ya no puede ser determinado desde el concepto de una razón pura práctica que corresponda a un sujeto metafísico nouménico en términos kantianos.

19 Ibíd.,p. 130.

20 Cf. Ibíd., p. 130.

21 Ibíd.,p. 130.

22 Ibíd., p.130. Recuérdese que Kant caracterizó el uso práctico de la razón como "la facultad o de producir -hervorzubringen-objetos-Gegenstände-correspondientes a representaciones -Vorstellungen- $\mathrm{o}$, por lo menos, de determinarse a sí misma, es decir, su causalidad, a la realización de esos objetos...” (Kant, I., Crítica de la razón práctica, ed. bilingüe, México DF., FCE, 2005, p.16).

23 Para las objeciones que se plantean en la identificación del concepto de la tradición política con el concepto de una cultura política y de esta con el concepto de unas instituciones objetivas determinadas vid.: Rodríguez Zepada, J., "El concepto de cultura política en El liberalismo político de John Rawls" en Quesada, F. (ed.), La filosofía política en perspectiva, Barcelona, Anthropos, 2011, pp. 212-225. 
El liberalismo postula, a diferencia de Kant, una razón pública práctica que corresponde a un sujeto concebido como una personal moral que sólo necesita contar con un sentido de la justicia y con la virtud de la razonabilidad. No cabe ya un compromiso con una concepción trascendental del bien como la que se sostuvo por parte de doctrinas filosóficas realistas o idealistas. Y es aquí, en una concepción política libre de toda fundamentación metafísica, religiosa o moral filosófica, donde ha de resolverse el desafío que para la estabilidad de nuestras sociedades contemporáneas representa el pluralismo. Sin posibilidad de apelar a algo más allá de la propia tradición política en su facticidad pero también en sus principios, no queda sino mantener la reflexión en el movimiento de una correlación que, aunque intencionalmente tienda a ello, no puede cerrar la propia experiencia política bajo el círculo de la reflexión. Por ello, aunque recuerde la poderosa imagen de la ciencia como un círculo de círculos, al modo hegeliano, para Rawls el movimiento de la reflexión que justifica la concepción política de la justicia se concreta en la imagen de unas correlaciones que no terminan de cerrarse metodológicamente en el círculo de una ciencia, esto es, de un saber en el que la experiencia quedara cerrada, asumida, reconciliada y comprehendida en un todo. Que sea posible la estabilidad en el espacio político depende exclusivamente de que los sujetos, como ciudadanos, mantengan un equilibrio entre la experiencia política y su capacidad para hacerse cargo de ella sin confiar en que la experiencia misma quede, en el télos del tiempo, recapitulada en la reflexión.

\section{Origen, trascendentalidad y visión}

Lo político, especificado de este modo, tiene, por decirlo así, que abrirse paso entre las diferentes concepciones sustantivas del bien para encontrar, en la propia tradición de la democracia liberal, los valores que puedan llevar a los ciudadanos, que viven bajo los paraguas de las diferentes concepciones del bien, a converger en una concepción política de la justicia y, más específicamente, en su núcleo ${ }^{24}$ : los principios de justicia. Cómo desde los valores políticos puede convergerse en un consenso es un problema que, en la orientación de nuestra investigación, sólo podrá hacerse una vez que profundicemos en el concepto de trasfondo social justo o eticidad. Pero antes de afrontar este tema es necesario reconsiderar la cuestión de la justificación de los principios de la justicia en relación a su pretensión de validez, una vez que hemos aceptado que la propia reflexión no puede elevarse sobre la experiencia política en su contexto social. Esta idea se ha expresado en la tesis de que los principios de la justicia, en tanto que se originan de hecho en una tradición determinada del pensamiento, han de quedar recluidos en la tradición desde la que emergieron. Esta sombra, que siempre ha acompañado la presentación de la concepción política de la justicia, presupone que la validez de su contenido viene a recaer y coincidir, como ha criticado entre otros Habermas ${ }^{25}$, con el hecho de su pertenencia a una tradición determinada. Pues bien, la fenomenología husserliana nos ha mostrado la posibilidad de encontrar un camino intermedio entre ambas tesis, haciéndonos ver cómo, aun partiendo de los hechos mismos,

24 Para la extensión del término "concepción" y su diferencia con el de "concepto" vid.: Rawls, J., El liberalismo..., p. 44, nota 15.

25 Cf. Palomar Torralbo. A., art. cit., p. 38-42. 
puede hallarse en la reflexión un fundamento de validez que, yendo más allá de ellos, pueda, sin embargo, sobrepasarlos, sin tener, por otra parte, que perder el suelo de la experiencia. Este tema se plantea en la fenomenología madura de Husserl a partir de la diferencia entre hecho (Tatsache) y esencia (Wesen). Aunque haya que establecer una diferencia radical entre hechos y esencias, la fenomenología sostiene que las esencias estructuran internamente los hechos y de tal manera que cabe una investigación de estas esencias. Estas se muestran como contenido de conciencia para un sujeto en la forma de una auto-donación originaria.

Esta investigación, que define el proyecto de la fenomenología, presupone irrenunciablemente una reflexión que poniendo entre paréntesis todo conocimiento pro-puesto nos lleva al origen donde las esencias se nos muestran en la forma de una visión. La fenomenología sostiene la tesis de que lo dado en esta visión es la fuente legítima de validez del conocimiento ${ }^{26}$. Toca ahora examinar si la reflexión en torno a la validez y justificación de los principios de la justicia puede clarificarse desde el modo como la fenomenología pensó la relación entre hechos y esencias. Este acercamiento a la concepción política de la justicia no parece un desatino si consideramos que los principios de la justicia no son expuestos como una mera generalización a partir de unos hechos históricos y que tampoco cabe fundamentarlos metafísicamente desgajados de estos hechos. Esta lectura fenomenológica de la concepción política de la justicia parte de un presupuesto esencial: que en lo político mismo ha de obrarse una apertura, como en la fenomenología, hacia la experiencia originaria de una visión esencial, visión que ahora tendría como contenido la idea de justicia que se expone en los principios. Esta apertura habría de producirse al menos en un doble nivel: como la apertura de la filosofía, como modo de justificación, a los principios de los justicia y como la apertura de los ciudadanos que sostienen las diferentes doctrinas comprehensivas a este origen con la finalidad de que sean ellos, en última instancia, los que lleven a cabo el consenso entrecruzado. Partamos para espejar este camino al origen, como ya abordara Husserl en la tercera de sus Investigaciones lógicas, del concepto de la relación de lo dependiente y de lo independiente como objeto de atención de una fenomenología particular de lo político.

Rawls sostiene la tesis de que, respecto a las propias doctrinas sustantivas del bien, la concepción de la justicia, tiene que mantener, "un punto de vista independiente"27. "Esto significa -afirma Rawls- que la concepción política puede ser presentada sin necesidad de afirmar, o de reconocer, o de aventurar conjeturalmente a qué doctrinas puede pertenecer o qué doctrinas pueden apoyarla" 28 . La concepción política de la justicia tiene que poder presentarse, utilizando el lenguaje de la fenomenología, poniendo entre paréntesis las diversas concepciones sustantivas del bien. Pero esta presentación independiente sólo puede llevarse a cabo si podemos elevarnos por encima de los propios puntos de vista o concepciones del bien que son dependientes de las doctrinas comprehensivas, realizando, de este modo, lo que la fenomenología llama un "cambio de actitud" (Einstellungsänderung). Esta expresión es acertada en tanto que ha de ser el filósofo político el que ha de poder presentar el contenido

26 Para esta idea, que remite al principio de todos los principios en fenomenología, vid.: Husserl, E., Ideas relativas a una fenomenología pura y una filosofía fenomenológica. Libro Primero: Introducción general a la fenomenología pura, México DF., FCE., 2013, pp. 129-130.

27 Rawls, J., El liberalismo..., p. 42.

28 Ibíd., p. 43. 
de la concepción política de la justicia independientemente del contenido de lo que se afirma en cada doctrina comprehensiva. Lo que caracteriza al filósofo es que en él puede operarse un cambio de actitud para alcanzar ese punto de vista independiente aunque él mismo sostenga en su vida ordinaria puntos de vista dependientes de alguna doctrina comprehensiva. La apertura a lo político, en primera instancia, sólo puede hacerse si quienes viven al amparo de una doctrina sustantiva desconectan el área de sus intereses particulares y de las creencias que los vinculan a esas doctrinas alcanzando un punto de vista independiente, es decir, filosófico. En El liberalismo político esta apertura al origen de lo político viene a pertenecer a aquel punto de vista expuesto en la posición original ${ }^{29}$.

La filosofía política tiene la tarea de construir la representación de esta posición. Esta ya es caracterizada por Rawls como una "interpretación filosófica" 30 de una situación inicial a la que, en tanto que re-presentación construida o re-construida, no se le confiere compromiso ontológico con hecho alguno. Aunque sostenida argumentalmente mediante la teoría de juegos y la teoría de la decisión racional, esta interpretación va encaminada a que los representantes de la posición original puedan disponer de las condiciones bajo las que son posibles saber qué es la justicia, es decir, las condiciones para verla en sus principios de manera independiente de las diferentes concepciones o ideas de la justicia sostenidas particularmente en las diversas doctrinas comprehensivas. Podría decirse que esta dis-posición metodológica obedece a la necesidad de aquilatar el significado del término "justicia" a partir del concepto originario de equidad o imparcialidad (fairness) $)^{31}$. La justificación de los principios de la justicia ha de presuponer metodológicamente salir del plexo de las creencias particulares de las doctrinas comprehensivas para, dejándolas en suspenso, alcanzar un punto de vista en el que pueda apreciarse originariamente el contenido de la idea de justicia. Esto, que aquí ha sido explicitado desde la fenomenología, es sostenido por Rawls cuando afirma que el constructivismo político viene a sustentarse, finalmente, en "una forma de ver la estructura y el contenido de una concepción política"32. Aquí "contenido" se refiere a los principios de la justicia y "estructura" al resultado de un procedimiento de construcción, según el cual "los agentes racionales, como representantes de los ciudadanos y sujetos a condiciones razonables, seleccionan los principios públicos de justicia que habrán de regular la estructura básica de la sociedad"33.

Rawls pretende evitar todo compromiso metafísico apostando por una hermenéutica de la posición original como un mero mecanismo de representación en el cual se "conceptualiza lo que aquí y ahora, consideramos como condiciones equitativas..." 34 . Los adverbios "aquí" y "ahora", tan importantes en el comienzo mismo de la otra fenomenología -la de la experiencia de la conciencia en Hegel-, señalan, por una parte, nuestra facticidad política, pero también señalan a esa facticidad como el espacio para una eticidad: aquel en el que se muestra nuestro horizonte de comprensión de la justicia. Sin embargo, en nuestras

29 Cf. Rawls, J., El liberalismo..., p. 58.

30 Rawls, J., Teoría de la justicia, México DF., FCE, 2010, p. 119.

31 Que esta noción es fundacional y, en este sentido, anterior al desarrollo de los principios de la justicia ha sido sostenido en: Sen, A., La idea de justicia, Madrid, Taurus, 2010, p. 83.

32 Rawls, J., El liberalismo..., p. 120. Cursiva mía.

33 Ibid., p. 120.

34 Ibíd., p. 56. 
condiciones postmetafísicas de pensamiento, esta eticidad ya no puede concebirse, como dijimos, sino como un trasfondo siempre abierto que ha de tener como referencia el sentido de la justicia que nos aparece representado en la posición original. De este modo, al tomar la idea de la posición original como "medio de reflexión y de autoclarificación" 35 se evita el compromiso "con una doctrina metafísica particular acerca de la naturaleza del yo más de lo que nuestra participación en una obra teatral, haciendo pongamos por caso, de Macbeth, o de Lady Macbeth, nos comprometería a pensar que somos realmente un rey o una reina embarcados en un lucha desesperada por el poder político" 36 .

La vuelta a la querida metáfora del teatro viene a reforzar en Rawls la tesis de que la concepción política de la justicia ha de quedar libre del compromiso de una filosofía primera en la que tuviéramos que representar a las partes de la posición original bajo algún tipo de teoría substancialista del yo. Hemos de reconocer, sin embargo, que los actores en la escena pública trazada en la posición original, aún siendo concebidos como meras representaciones, han de encarnar a esos personajes de tal manera que a través de ellos puedan ver lo que, siguiendo con la metáfora, aquellos que están fuera del escenario no ven. Pero, si esto es así, el acceso a la posición original no queda al margen de un compromiso filosófico importante: el compromiso de ver lo que para otros es aún no visible. La posición original dibuja, de este modo, la posibilidad de ver bajo una posición metodológicamente privilegiada el contenido mismo de unos principios. Las partes de la posición original pueden ser despojadas de cualquier rasgo sustancial metafísico hasta ser pensadas como meras representaciones en un mecanismo general de representación o incluso, hablando con Shakespeare, como meros espectros, pero lo que no puede despojarse de ellas es la capacidad de poder ver los principios originariamente a partir de la descripción con la que se ha construido la situación original.

Pero, fenomenológicamente, esto no estaría claro si pensáramos que las partes de la posición original, las partes representadas en ella, son los sujetos que han de ver el contenido de la justicia. No son ellos los que han de llevar a cabo el cambio de actitud, sino nosotros, como filósofos políticos, en ellos. Este yo es el que corresponde al que viene dado según el punto de vista "nuestro, el de ustedes y el mío, que estamos empeñados en elaborar la justicia como equidad y en explorarla como concepción política de la justicia" ${ }^{37}$. Bajo este punto de vista, se intenta que nosotros, en tanto que nos disponemos a la construcción de la posición original, abramos nuestra mirada a lo que sería visto por las partes representadas en ella, con el fin de que la concepción de la justicia pueda construirse independientemente del contenido de las creencias e intereses sostenidos en una doctrina comprehensiva. Somos nosotros los que tenemos que abrirnos a ese origen de lo político abierto él mismo en nuestra dis-posición para situarnos como los actores que representan a las partes de la posición original. Nosotros hemos de ver lo representado en el escenario como si fuera visto por ellos. Las partes representadas en la posición original son, por decirlo así, nuestros primeros ojos. Por ello, es nuestra intencionalidad de ver los principios de la justicia originariamente lo que nos lleva al montaje de esa curiosa representación con "esas criaturas artificiales" 38 a las que hemos dado virtualmente vida

35 Ibíd., p. 56.

36 Ibíd., p. 58.

37 Rawls, J., El liberalismo..., p. 58.

38 Ibíd., p. 58. 
en la posición original y somos nosotros, en tanto que "criaturas naturales" pero dispuestas a la reflexión, los que tenemos que hacer el esfuerzo por construir una concepción de la justicia partiendo de lo visto ahí en la representación.

En el lenguaje de la tradición metafísica de raigambre platónica, que nos lleva hasta el idealismo trascendental de Husserl, a aquello que es objeto de una visión intelectual y no meramente una observación de hechos se denomina "ideas" o "esencias". Es lo que Husserl llamaba "visión de esencia" (Wesensschau) o "visión de lo esencial" (Wesenerschauung) que para él comprometía, a partir de Ideas I, un tipo de investigación trascendental. La reflexión trascendental es aquella que sobrepasa la investigación de las cuestiones de hecho para adentrarse en el campo que se despliega para las cuestiones eidéticas que son las que dan derecho a hablar de una visibilidad originaria, de una visibilidad que puede tomar la forma última de la evidencia. "En la evidencia, -escribe, por ejemplo, Husserl en el parágrafo cuatro de las Meditaciones Cartesianas - a diferencia del mero mentar lejano a las cosas, está presente la cosa misma como ella misma..." 39 . Esta evidencia es la fuente de legitimidad del conocimiento válido.

Pues bien, la crítica de Rawls al realismo y al idealismo trascendental no puede implicar el rechazo de un sujeto que pueda ver de forma originaria, yendo más allá de los hechos, el contenido de los principios de la justicia y mostrarlo como la experiencia de algo que puede ser visto. Esto no implica que el contenido de la concepción política de la justicia esté dado en un orden metafísico de ideas, ni tampoco que este contenido ideal se constituya en la realidad según los principios del idealismo, sino que, como contenido, se hace presente, esto es, visible, para nosotros en tanto que sujetos que pueden llevar a cabo una representación originaria de la idea de justicia como una dis-posición de nuestra reflexión.

Desde la fenomenología, esta intencionalidad conlleva la tarea de emprender para nuestra mirada un camino de vuelta a la posición original para ver y aceptar desde ahí los principios de la justicia. Este camino se nombra bajo el concepto de reducción. Para emprenderlo es necesario que echemos el velo de la ignorancia sobre aquellos contenidos morales que vienen dados naturalmente como puntos de vista comprehensivos y que desacostumbremos nuestra mirada de su contemplación para pre-disponerla en la reflexión a una originaria visión. Pero lo interesante en el planteamiento de Rawls, al igual que en el planteamiento husserliano, según hemos descrito en la segunda parte de nuestro trabajo, es que no cabe cancelar, en algún momento de tiempo, el recurso a la posición original porque la experiencia quede en el saber de una filosofía primera elevada a concepto. Tras la quiebra de la metafísica, ya no podemos tener garantías de que el equilibrio reflexivo, de lograrse, cerrara todas las correlaciones en el círculo de una reflexión. Pero, por ello, precisamente, no puede prescindirse tampoco de la reflexión que nos devuelve la mirada a la representación del contenido originario de la justicia.

Por último, aunque ya no podamos entrar en ello, hay que señalar que el punto de vista más interesante en el liberalismo político no es el que corresponde a las partes de la posición original ni al nuestro que, en definitiva, es el punto de vista del teórico o del filósofo, sino el punto de vista de los "ciudadanos en una sociedad bien ordenada" 40 . Ciertamente, la finalidad última de El liberalismo político es que los ciudadanos pongan en el centro de un consenso

39 Husserl, E., Meditaciones cartesianas, Madrid, Tecnos, 1986, p. 16.

40 Rawls, J., El liberalismo..., p. 58. 
entrecruzado la concepción política de la justicia, pues son ellos y no el filósofo o teórico en su reflexión los que han de construir desde las instituciones el trasfondo ético para asegurar la estabilidad social. Pero, para ello, es necesario que ellos mismos lleven a cabo un cambio de actitud para ver el contenido de la concepción política de la justicia yendo más allá de las cosmovisiones de las doctrinas comprehensivas en las que naturalmente viven. Tras la apertura a lo político desde el "nosotros" como filósofos ha de abrirse lo político mismo al "nosotros" como ciudadanos. Sólo si los ciudadanos ven lo que los filósofos han visto en la posición original, sólo si los ciudadanos ponen en práctica la epojé y emprenden el camino de la reducción de las creencias que sostienen en sus propias doctrinas comprehensivas hacia las ideas que, en formas de principios, pueden verse en la posición original, podrán dar su apoyo a la concepción política de la justicia en un consenso entrecruzado y sólo así, ulteriormente, podrá definirse correctamente la práctica del consenso. Que esto comprometa una filosofía trascendental o, más aún, que el propio constructivismo, en tanto que supone una forma de ver, haya de ser desplazado por un método filosófico al modo fenomenológico es otra cuestión en la que no podemos entrar ya, pero, en cualquier caso hemos visto que es posible no sólo interpretar fenomenológicamente el liberalismo político, como hemos hecho en las dos primeras partes de nuestro trabajo, sino también clarificarlo con los conceptos con los que opera la propia reflexión fenomenológica.

\section{Conclusión}

Cabe, por tanto, profundizar en una lectura de la concepción de la justicia desde el camino abierto por la fenomenología. Esta lectura se basa en que tanto una como otra requieren en sus respectivas metodologías de una vuelta al origen. Esta vuelta es la condición primera para que pueda iniciarse el movimiento de una correlación entre experiencia y reflexión. La expresión "equilibrio reflexivo" señala que ya no es posible dar por cerradas aquellas correlaciones a las que apuntábamos, pero señala igualmente que, pese a todo, nuestras sociedades democráticas necesitan, para mantenerse establemente, un equilibrio entre su interna e inerradicable conflictividad y el ideal de una sociedad en la que se vieran cumplidos los principios de la justicia, aunque sepamos que lo visto como contenido en el origen no quedará como algo plenamente realizado. Pero, por esto mismo, no podemos renunciar a que lo visto originariamente esté presente en nuestra facticidad, señalando intencionalmente el camino de la relación entre experiencia y reflexión. En la fenomenología, esta idea se expresa en la tesis de que el trabajo de constitución de la subjetividad tiene como correlato el sentido del mundo y que el sentido del mundo encuentra siempre a su término la subjetividad, es decir, que la correlación misma no puede darse en algún momento de tiempo por finalizada, cancelada y cerrada. Una fenomenología de lo político, como una ontología regional, tiene como objeto de análisis ese mundo constituido como un espacio político que, vertebrado institucionalmente, es correlato de la intersubjetividad.

En nuestra lectura, hemos ensayado este camino buscando relacionar el método fenomenológico husserliano y el método del constructivismo rawlsiano en torno al problema del origen y la validez. De esta lectura, cabe afirmar lo siguiente: si la epojé y la reducción son posibles, entonces lo son el velo de la ignorancia y la posición original. Si la empresa de Husserl no lo fuera, tampoco lo sería la de Rawls. Ambas comparten el supuesto filosófico 
moderno fundamental, que proviene en un caso del cartesianismo y en otro de las teorías contractuales, de que es posible metodológicamente la vuelta a un origen en el cual puede, en un caso, fundarse una filosofía primera, en otro, justificarse una teoría o una determinada concepción de la justicia.

Que cabe este acercamiento no sólo se hace patente en el modo en el que la fenomenología de Husserl nos hace profundizar en los supuestos filosóficos que Rawls puso en juego en su constructivismo, sino también en el modo en el que la vuelta a la posición original de Rawls señala claramente el motivo ético que está presente en la reducción fenomenológica de Husserl. Por una parte, sólo si nos situamos teóricamente en la posición original, puede estimarse prácticamente el asunto de la equidad, pero sólo si tenemos una motivación ética, que no se contenta con aceptar como definitivamente dada una realidad constituida, puede llevarse a cabo la reducción. Aquilatar el conocimiento volviendo a la experiencia del origen sólo es posible si quien emprende la tarea de poner en práctica la reducción se sitúa en una actitud de reflexión motivada éticamente por la imparcialidad. El yo puro práctico, como sujeto último que elige los principios de la justicia, puede elucidarse como sujeto teórico a través del trabajo de un yo filosófico que lleva en sí la capacidad de desconectar el área de sus intereses particulares para posicionarse en un origen en el cual puede adoptar una perspectiva o punto de vista independiente. Pero, a su vez, el yo puro teórico, como sujeto último que puede adoptar esta actitud sólo puede elucidarse prácticamente en la medida en que la reducción es una práctica que presupone originariamente la imparcialidad. Situarse en la posición original, como mirada propia del sujeto práctico, es ya una indicación de la propia capacidad del sujeto para adoptar un punto de vista independiente. Esta capacidad presupone la libertad. Sin libertad no podríamos sobrepasar el mundo de los hechos en su manifestación plural para llegar a la posición que re-une la mirada en un origen. A partir de este cruce primero de la fenomenología con el liberalismo político, pueden abrirse, sin duda, otros caminos para un diálogo fecundo entre la fenomenología como un saber de la experiencia y una filosofía política que no puede renunciar, pese a la crítica de la tradición metafísica, a la tarea de la reapropiación originaria del contenido de una idea de justicia dada como un principio irreductible para la constitución del espacio político democrático. En esta reapropiación, como hemos mostrado, está en juego la posibilidad de que la justificación de una concepción de la justicia sea sostenida en el espacio público por cuantos ciudadanos ya viven en las creencias de sus doctrinas comprehensivas razonables. Pero, para ello, como se ha indicado, los ciudadanos habrán de ver a su modo lo que el filósofo político ve, para salir del plexo de sus creencias particulares hacia el foco que pone la luz en una determinada concepción de la justicia.

\section{Bibliografía citada}

Barry, B. (1995), "John Rawls and the Search for Stability", Ethics (Chicago), Vol. 105, n. 4, pp. 874-915.

Dombrowski, D. A. (2001), Rawls and Religion. The Case for Political Liberalism, Albany, State University of New York Press.

Finlayson, J. G. and Freyenhagen F. (ed.) (2011), Habermas and Rawls. Disputing the Political, New York, Routledge.

Hegel, G.W.F. (1969), Werke 6, Frankfurt a. M., Suhrkamp Verlag. 
Husserl, E. (1986), Meditaciones cartesianas, Madrid, Tecnos.

Husserl, E. (2013), Ideas relativas a una fenomenología pura y una filosofía fenomenológica, México DF, FCE.

Kant, I. (2005), Crítica de la razón práctica, ed. bilingüe, México DF., FCE.

Melero de la Torre, M. C. (2010), Rawls y la sociedad liberal. El proyecto de la neutralidad política, Madrid, Plaza y Valdés Editores, pp. 54-55.

Muguerza, J. (2005), "Razonabilidad" en Cerezo Galán, P. (ed.), Democracia y virtudes cívicas, Madrid, Biblioteca Nueva, pp. 121-129.

Muguerza, J. (2010), "Prólogo" a Melero de la Torre, M. C., cit., pp. 16-17.

Palomar Torralbo, A. (2007), "Tensión y complejidad en la teoría crítica de la sociedad y discursiva del derecho", Alfa. Revista de la Asociación andaluza de filosofía, Vol. XXI, pp. 30-51.

Parekh, B. (2005), Pensadores políticos contemporáneos, Madrid, Alianza Editorial, pp. 287-288.

Rawls, J. (1993), Political liberalism, New York, Columbia University Press.

Rawls, J. (1996), El liberalismo político, Barcelona, Crítica.

Rawls, J. (2010), Teoría de la justicia, México DF., FCE.

Rex, M., "Overlapping consensus"en Mandle, J. and Reidy D. A. (ed.), A Companion to Rawls, Oxford, Wiley-Blackwell, pp. 283-285.

Rodríguez Zepada, J. (2011), "El concepto de cultura política en El liberalismo político de John Rawls" en Quesada, F. (ed.), La filosofía política en perspectiva, Barcelona, Anthropos.

Seleme, H., "El problema de la estabilidad", Doxa. Cuadernos de filosofía del derecho, n 24, 2001, pp. 297-318.

Sen, A. (2010), La idea de justicia, Madrid, Taurus. 